\title{
Simulation of storm surge inundation under different typhoon intensity scenarios: case study of Pingyang County, China
}

\author{
Xianwu Shi ${ }^{1,2,4}$, Pubing Yu ${ }^{3}$, Zhixing Guo ${ }^{1}$, Zhilin $\mathrm{Sun}^{2}$, Fuyuan $\mathrm{Chen}^{2}$, Xiuguang $\mathrm{Wu}^{2}$, Wenlong Cheng ${ }^{2}$, and \\ Jian Zeng $^{2}$ \\ ${ }^{1}$ National Marine Hazard Mitigation Service, Beijing, 100194, China \\ ${ }^{2}$ Ocean College, Zhejiang University, Hangzhou, 310058, China \\ ${ }^{3}$ Zhejiang Institute of Hydraulics and Estuary, Hangzhou, 310020, China \\ ${ }^{4}$ Key Laboratory of Coastal Disaster and Protection, Ministry of Education, Hohai University, Nanjing, 210098, China
}

Correspondence: Jian Zeng (zengjian@zjwater.gov.cn)

Received: 30 December 2019 - Discussion started: 5 February 2020

Revised: 7 September 2020 - Accepted: 13 September 2020 - Published: 21 October 2020

\begin{abstract}
China is one of the countries that is most seriously affected by storm surges. In recent years, storm surges in coastal areas of China have caused huge economic losses and a large number of human casualties. Knowledge of the inundation range and water depth of storm surges under different typhoon intensities could assist predisaster risk assessment and making evacuation plans, as well as provide decision support for responding to storm surges. Taking Pingyang County in Zhejiang Province as a case study area, parameters including typhoon tracks, radius of maximum wind speed, astronomical tide, and upstream flood runoff were determined for different typhoon intensities. Numerical simulations were conducted using these parameters to investigate the inundation range and water depth distribution of storm surges in Pingyang County considering the impact of seawall collapse under five different intensity scenarios (corresponding to minimum central pressure values equal to 915 , $925,935,945$, and $965 \mathrm{hPa}$ ). The inundated area ranged from 103.51 to $233.16 \mathrm{~km}^{2}$ for the most intense typhoon. The proposed method could be easily adopted in various coastal counties and serves as an effective tool for decision-making in storm surge disaster risk reduction practices.
\end{abstract}

\section{Introduction}

China is among the few countries affected seriously by storm surges. A storm surge can cause overflow of tide water and seawall destruction that can result in flooding in coastal ar- eas, which can be extremely destructive and can have a serious impact on surrounding areas (Sun et al., 2015). Storm surges have occurred along much of China's coast from south to north (Gao et al., 2014). On average, approximately nine typhoons make landfall over China annually (Shi et al., 2015), most of which cause storm surges. In 2018, storm surge disasters caused coastal flooding in China that resulted in three deaths and direct economic losses of RMB 4.456 billion (Ministry of Natural Resources of China, 2019). With the recent rapid socioeconomic development in China, industrialization and urbanization processes in coastal areas have accelerated, and both the population density and the social wealth in such areas have increased sharply. Concurrently, owing to global climate change and sea level rise, the occurrence of weather situations that trigger storm surges has become more frequent and the associated risk level of coastal storm surges has increased significantly (Fang et al., 2014). Fortunately, the number of fatalities in China due to storm surges has decreased significantly because of improvements in the regional early-warning capability (Shi et al., 2015). Thus, the focus on storm surge disasters has changed from reduction in disaster losses to mitigation of disaster risks. Therefore, research on storm surge risk has attracted more and more attention (Shi et al., 2020a).

Storm surge risk assessment aims to estimate the risk level of storm surges in a certain region based on deterministic numerical simulation in combination with designed probabilistic storm surge scenarios (Shi et al., 2013; Wang et al., 2018). The calculation of storm surges under scenarios with 
storms of different intensity is an important part of storm surge risk assessment. The calculation results could provide important decision-making support for the response to storm surges in coastal areas, and they could assist in both the preassessment of storm surge disasters and the preparation of storm surge emergency evacuation plans. Following the earthquake-induced " 3.11 " tsunami that occurred in Japan in 2011, scientific research on many aspects of marine disaster risk management became of great concern to various governments. With consideration of storm surge disaster as the primary hazard, China commenced a project for marine disaster risk assessment and zoning, and it subsequently released its marine industry standard, the Technical Guidelines for Risk Assessment and Zoning of Marine Disaster Part 1: Storm Surge (Liu et al., 2018). Calculation of the inundation range and water depth of storm surges associated with typhoons of different intensity is one of the most important tasks in storm surge risk assessment.

The core element of simulation of inundation by storm surge disaster under scenarios of different typhoon intensities is to set key parameters for both the typhoons and the storm tides (e.g., typhoon track, typhoon intensity, radius of maximum wind speed, and astronomical tide) under different conditions (Shi et al., 2020a, b). Tomohiro et al. (2010) set key parameters for the largest possible typhoon-induced storm surge in different regions of Japan by simulating typhoon track translation using indicators of the Ise Bay typhoon (the most serious typhoon event recorded in Japan's history) as reference typhoon parameters. To overcome the limitation of historical records, a stochastic modeling method has been developed for simulation of typhoon track and intensity. This method is to analyze the statistical probability characteristics of historical typhoons in terms of their annual frequency, seasonal distribution, track distribution, intensity, and influence areas. Based on these features, the generation, development, and lysis of typhoons can be simulated to generate a large number of typhoon events (Powell et al., 2005; Lin et al., 2010). By selecting events with different typhoon intensity from the generated samples, the inundation extents and depths of the study area can be calculated using the storm surge numerical model (Wood et al., 2005; Wahl et al., 2015), and this research mainly focuses on the coast of the North Atlantic Ocean. Considering the typhoon landing and historical storm surge events that have happened in the coastal areas of China, how to set the parameters for performing the simulation of typhoon-induced storm surges under different typhoon intensity scenarios is an interesting and important topic regarding the coast of China.

This study considered Pingyang County of Zhejiang Province (China) as a case study area. The objective was to propose a deterministic method to calculate the inundation extents and depths caused by different typhoon intensity scenarios combined with the storm surge numerical model. The key parameters (e.g., typhoon intensity, typhoon track, maximum wind speed radius) corresponding to the characteristics of typhoons landing in the coastal areas of China were set. The astronomical tide, upstream flood runoff, and seawall collapse were taken into consideration as important factors in the storm surge simulation. The results aim to contribute to the methodology of quantitative assessment of storm surge hazards for coastal counties.

\section{Materials}

\subsection{Case study area}

Pingyang County is a coastal county belonging to the city of Wenzhou in Zhejiang Province, China (Fig. 1), and is affected most frequently by storm surges in coastal areas. It is located in the tropical storm zone of the western $\mathrm{Pa}$ cific Ocean and is generally exposed to the risk of storm surges during July-October. Pingyang County lies within the region $27^{\circ} 21^{\prime}-27^{\circ} 46^{\prime} \mathrm{N}, 120^{\circ} 24^{\prime}-121^{\circ} 08^{\prime} \mathrm{E}$, and it is bordered by Rui'an, Wencheng, Taishun, and Cangnan counties. The county extends roughly $83 \mathrm{~km}$ from east to west and roughly $25.4 \mathrm{~km}$ from north to south, covering an area of approximately $1051 \mathrm{~km}^{2}$. It is a highly developed and densely populated area of China with considerable asset exposure. Pingyang County has a population of approximately 800 000, and it is the first National Coastal Economic Open County with customs, ports, and important industries. The coastal zone of Pingyang County, which extends for $22 \mathrm{~km}$, is surrounded by sea on its eastern, southern, and northern sides. The Ao Jiang and Feiyun Jiang flow across the county, and they discharge into the East China Sea. Storm surges frequently hit this county, which is one of the reasons why the China State Oceanic Administration approved Pingyang County as the first National Marine Disaster Mitigation Comprehensive Demonstration Area in China.

\subsection{Data}

Multisource data (Table 1) were collected to perform storm surge numerical modeling in Pingyang County. The digital elevation map (DEM) of Pingyang County and nearshore submarine topography data were collected to construct the numerical model, and tidal observational data were used to validate the model. Historical typhoon records, including time, location, and intensity, were collected to set the typhoon parameters driving the storm surge numerical model. A field survey was carried out by the Zhejiang Institute of Hydraulics and Estuary to investigate the inundation situation along the Ao Jiang in Pingyang County. Researchers equipped with GPS RTK (Global Positioning System realtime kinematic) receivers and rangefinders worked in two groups to make measurements from 2 to 7 October 2013. The extent of the inundation was estimated based on flooding marks, such as the accumulation of trash, signs of mud, and withered plants. In addition, the extent of inundation was established through interviews with local residents. 


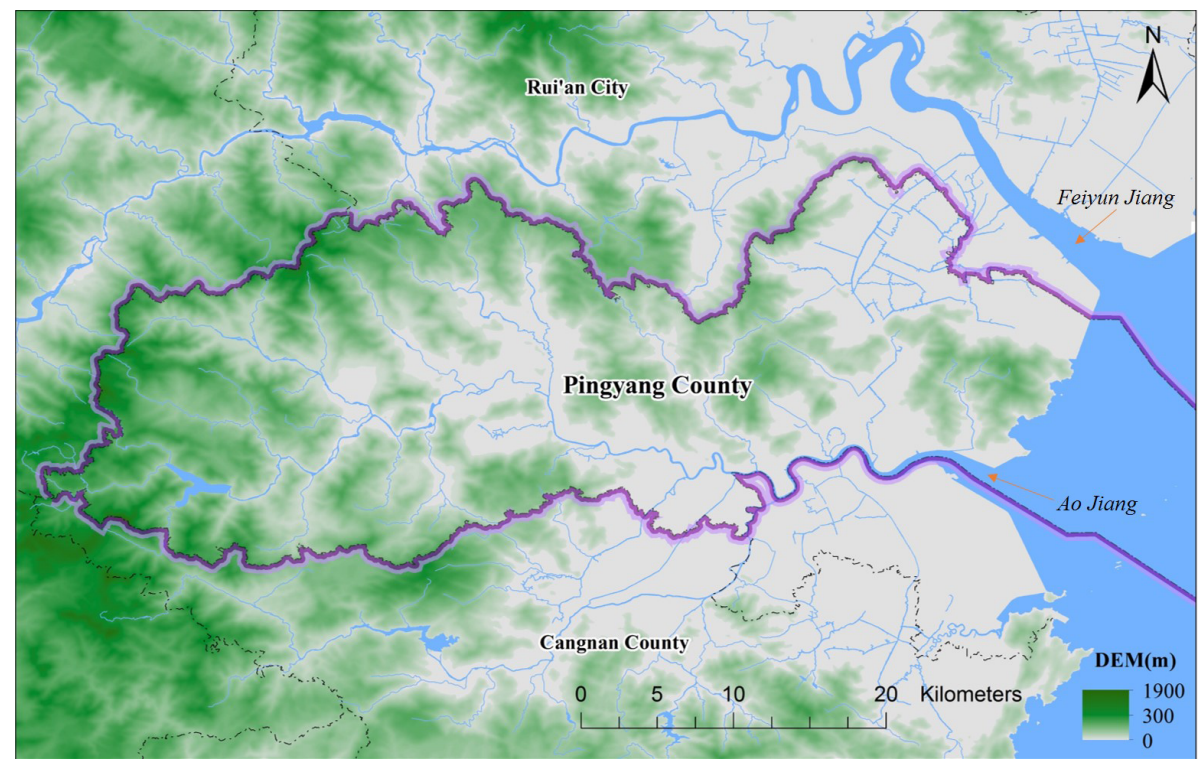

Figure 1. Case study area.

Table 1. Multisource data used to perform storm surge numerical modeling in Pingyang County.

\begin{tabular}{lrll}
\hline Data type & Time series & Description & Source \\
\hline $\begin{array}{l}\text { Historical typhoon } \\
\text { records }\end{array}$ & 1949-2018 & $\begin{array}{l}\text { Time, location, and intensity of } \\
\text { each typhoon track point }\end{array}$ & $\begin{array}{l}\text { Shanghai Typhoon Institute, } \\
\text { China Meteorological } \\
\text { Administration }\end{array}$ \\
\hline $\begin{array}{l}\text { Digital elevation } \\
\text { map and } \\
\text { submarine } \\
\text { topography }\end{array}$ & 2015 & $\begin{array}{l}\text { Digital elevation map of } \\
\text { Pingyang County and offshore } \\
\text { submarine topography }\end{array}$ & $\begin{array}{l}\text { Surveying and Mapping } \\
\text { Bureau of Zhejiang Province }\end{array}$ \\
\hline $\begin{array}{l}\text { Tidal } \\
\text { observational data }\end{array}$ & $1990-2015$ & $\begin{array}{l}\text { Hourly observational data of } \\
\text { surge and water level for tidal } \\
\text { station during typhoon periods }\end{array}$ & $\begin{array}{l}\text { East China Sea Marine } \\
\text { Forecasting Center, Oceanic } \\
\text { Administration of China }\end{array}$ \\
\hline $\begin{array}{l}\text { Historical } \\
\text { inundation ranges }\end{array}$ & 2013 & $\begin{array}{l}\text { Inundation ranges caused by } \\
\text { Fitow along the Ao Jiang in } \\
\text { Pingyang County }\end{array}$ & $\begin{array}{l}\text { Field surveying by Zhejiang } \\
\text { Institute of Hydraulics and } \\
\text { Estuary }\end{array}$ \\
\hline
\end{tabular}

\section{Methods}

This study proposed a framework for calculation of storm surge inundation simulation under different typhoon intensity scenarios (Fig. 2). The proposed framework was composed of four parts: model configuration, model validation, parameter setting, and inundation simulation. The numerical model was used to simulate the storm-surge-inundated range and water depth, and the DEM and nearshore submarine topography data were used to construct the storm surge numerical model. The numerical model was validated by historical observational data of tidal stations and field-surveying data of inundated areas. Based on the historical observational data, the key parameters (e.g., typhoon track, radius of maximum wind speed, astronomical tide, and upstream flood runoff) could be set to drive the storm surge numerical model. The proposed method could be easily adopted in various coastal counties and serves as an effective tool for decision-making in storm surge disaster risk reduction practices.

\subsection{Model configuration}

The typhoon-astronomical-flood-wave coupled numerical model used in this study, developed by the Zhejiang Institute of Hydraulics and Estuary, is based on the unstructuredgrid finite volume method, and more detailed model information can be found in Chen et al. (2019). It has characteristics of high efficiency, accuracy, conservation, and the automatic capture of intermittent flow. This model could be used to sim- 


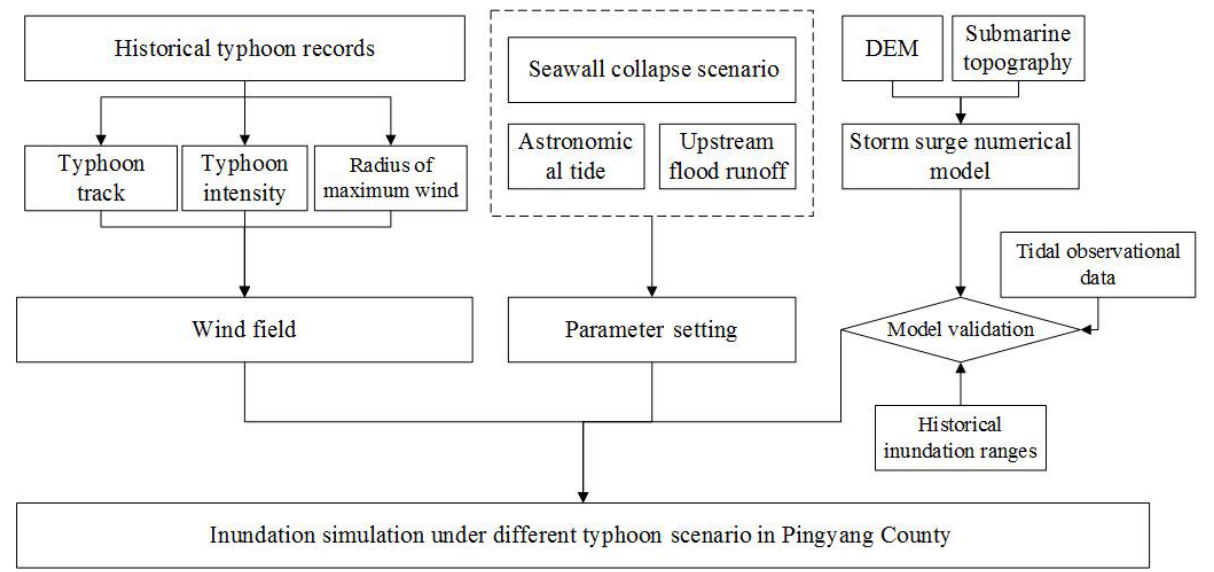

Figure 2. Framework of storm surge inundation simulation under different typhoon scenarios in Pingyang County.
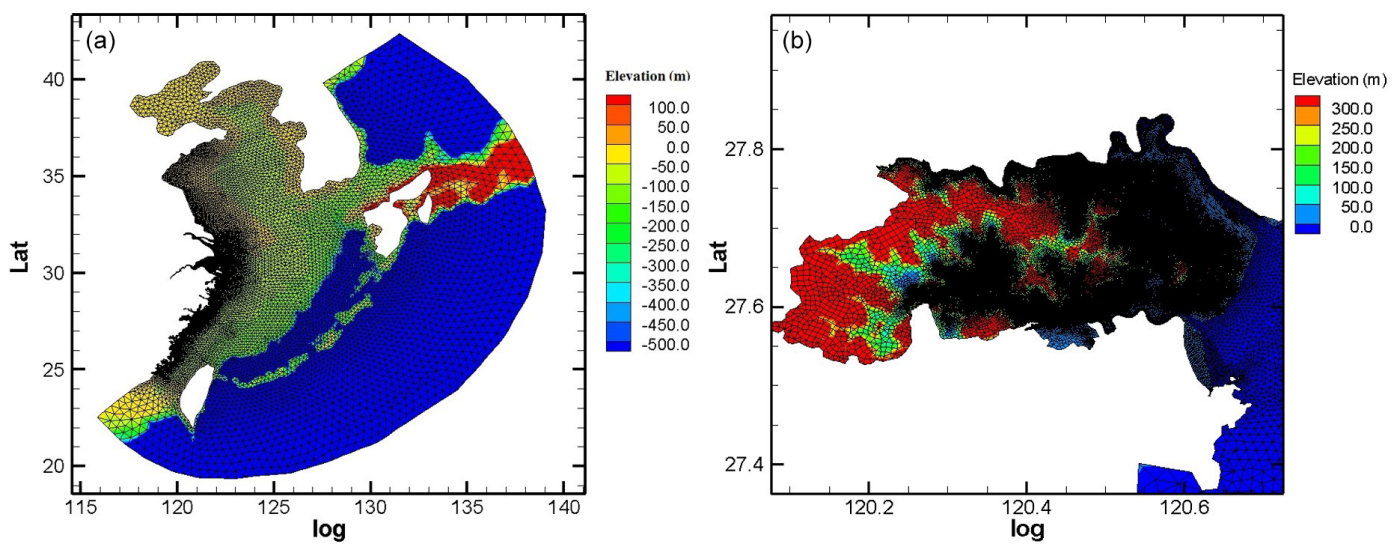

Figure 3. (a) Computational domain of the numerical model in the offshore area and (b) refined mesh in Pingyang County.

ulate conventional river channel flow and offshore water flow including flood evolution, astronomical tides, storm surges, and flooding. The storm surge simulations were performed in combination with the calculation of river runoff and consideration of typhoon wind and air pressure fields. Thus, the model was capable of simulating large-scale detailed storm surge flooding. The open-sea boundary of the model was set near the first typhoon warning line in China's offshore area (Fig. 3a). The model contained triangular and quadrilateral grids consisting of 258543 units and 173910 nodes. The coverage extended to Bohai Bay and the Sea of Japan in the north, to the south of Taiwan in the south, and to the east of the Ryukyu Islands (Fig. 3a) in the east. The upper boundary of the Ao Jiang was set at Daitou; the upper boundary of the Feiyun Jiang was at Zhaoshandu; and the upper boundary of the Oujiang was set at Weiren. The grid for the offshore area and land in Pingyang County with elevation of $<30 \mathrm{~m}$ (including Nanji Island) had a side length of 50-200 m, and the minimum side length was $15 \mathrm{~m}$ (Fig. 3b). The model covered the Bohai Sea, Yellow Sea, East China Sea, Sea of Japan, Korean Strait, Taiwan Strait, Yangtze River estuary, Hangzhou
Bay, and Qiantang River. The mesh grid was finest in localized areas of the Zhejiang offshore region, Oujiang estuary, Feiyun Jiang estuary, and Ao Jiang estuary.

Waves caused by typhoons are simulated by the Simulating Waves Nearshore (SWAN) model in this study (Booij et al., 1999). The SWAN model is a third-generation numerical wave model, which is used to simulate wind-generated wave propagation in coastal regions. It can describe the evolution of wave fields under specific wind, flow, and underwater terrain conditions in shallow waters. The governing equation is as follows.

$\frac{\partial}{\partial_{t}} N+\frac{\partial}{\partial_{x}} C_{x} N+\frac{\partial}{\partial_{y}} C_{y} N+\frac{\partial}{\partial_{\sigma}} C_{\sigma} N+\frac{\partial}{\partial_{\theta}} C_{\theta} N=\frac{S}{\sigma}$

In the equation, $N$ is wave action, $\sigma$ is relative frequency of waves, $\theta$ is wave direction, and $S$ is source item. $C_{x}$ and $C_{y}$ are wave propagation speed in the $x$ and $y$ direction, respectively. $C_{\sigma}$ is propagation speed of wave action in frequency space, and $C_{\theta}$ is the propagation speed of wave action in wave direction space. Based on the wave elements and the structural parameters of the seawall, the overtopping 
discharge is calculated by the empirical formula. In the simulation of dike breaching, the varying dike top elevation is applied according to overtopping discharge to simulate the process of dike breaching.

\subsection{External force}

The storm surge numerical model was driven by wind stress and the atmospheric pressure gradient acting on the surface. The Jelesnianski model was chosen to generate the wind and pressure fields (Jelesnianski, 1965), for which the calculation formulas are as follows:

$$
\begin{aligned}
& W= \begin{cases}\frac{r}{r+R}\left(V_{0 x} \bar{i}+V_{0 y} \bar{j}\right)+W_{R}\left(\frac{r}{R}\right)^{\frac{3}{2}} \frac{(A \bar{i}+B \bar{j})}{r,(0<r \leq R)} \\
\frac{R}{r+R}\left(V_{0 x} \bar{i}+V_{0 y} \bar{j}\right)+W_{R}\left(\frac{R}{r}\right)^{\beta} \frac{(A \bar{i}+B \bar{j})}{r,(r>R)}\end{cases} \\
& P_{a}= \begin{cases}P_{0}+\frac{1}{4}\left(P_{\infty}-P_{0}\right)\left(\frac{r}{R}\right)^{3}, & (0<r \leq R) \\
P_{\infty}-\frac{3}{4}\left(P_{\infty}-P_{0}\right) \frac{R}{r}, & (r>R)\end{cases}
\end{aligned}
$$

and

$$
\begin{aligned}
& A=-\left[\left(x-x_{\mathrm{c}}\right) \sin \theta+\left(y-y_{\mathrm{c}}\right) \cos \theta\right], \\
& B=\left(x-x_{\mathrm{c}}\right) \cos \theta+\left(y-y_{\mathrm{c}}\right) \sin \theta .
\end{aligned}
$$

In the above equations, $R$ is the radius of maximum wind speed; $r$ is the distance from the calculated point to the center of the typhoon; $\left(V_{0 x}, V_{0 y}\right)$ is the translation speed of the typhoon; $(x, y)$ and $\left(x_{\mathrm{c}}, y_{\mathrm{c}}\right)$ are the coordinates of the calculated point and the typhoon center, respectively; $\theta$ is the inflow angle; $P_{0}$ is the central pressure of the typhoon; $P_{\infty}$ is the atmospheric pressure at an infinite distance; and $W_{R}$ is the maximum wind speed of the typhoon.

\subsection{Model verification}

Verification of the storm surge numerical model was performed using 20 typhoon-induced storm surge events that affected Pingyang County during 1990 to 2015 . The tidal range along Pingyang coast is about $4.45 \mathrm{~m}$. The differences between the simulated and observed water level and surge of the 20 typhoon-induced storm surge events were compiled at six tidal stations (Jiantiao, Haimen, Kanmen, Dongtou, Rui'an, and Aojiang as shown in Fig. 4) close to Pingyang County as shown in Tables 2 and 3. According to the statistical results, the absolute average error in the water level of all involved tidal stations was $12-18 \mathrm{~cm}$ and the absolute average maximum storm surge error in all involved tidal stations was $11-15 \mathrm{~cm}$. A storm surge caused by Typhoon Fitow (no. 1323) is the most serious event that has affected Pingyang County in the past 10 years. Verification of the water level and storm surge at six tidal stations affected by Typhoon Fitow (no. 1323) is presented in Figs. 5 and 6, respectively. It can be seen that both the phase and the water level

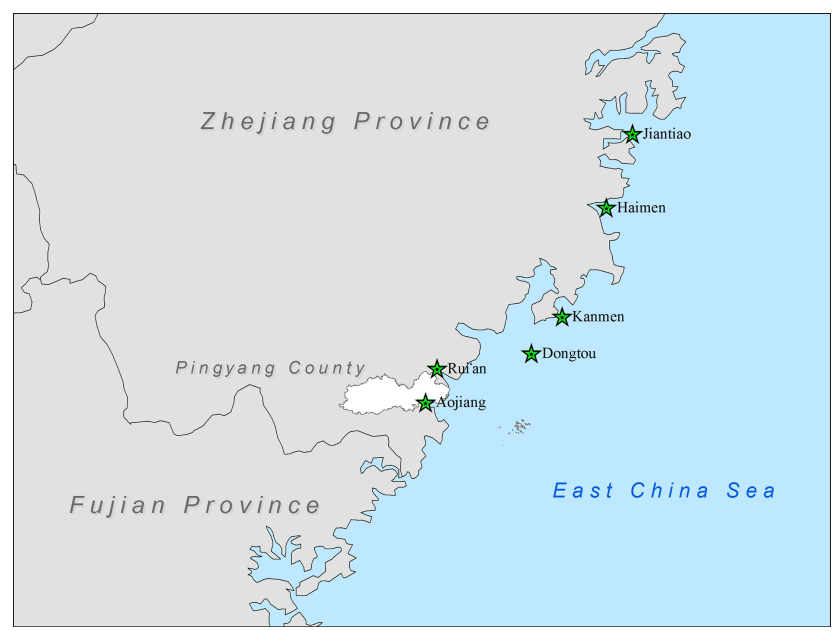

Figure 4. The distribution of tidal stations along the coastal Zhejing Province.

obtained from the storm surge simulation are highly consistent with the actual measurements, proving that the storm surge numerical model developed in this study was reliable.

Besides, a validation for the inundation simulation was performed based on the inundation ranges through field surveying. The model described above was used to perform a simulation of the area along the Ao Jiang (Pingyang County) inundated by Typhoon Fitow. A field survey was undertaken by the Zhejiang Institute of Hydraulics and Estuary to investigate the inundation areas in Pingyang County during the storm surge disaster period caused by Fitow (Fig. 7b). The simulated and investigated inundation areas were compared (Fig. 7). It can be seen that the surveyed and simulated inundated areas are similar. The extent of the surveyed inundated area was slightly larger than that simulated because typhoon precipitation during the period of influence of Fitow caused urban waterlogging in parts of Pingyang County.

\subsection{Parameter setting}

\subsubsection{Typhoon intensity}

Pingyang County is frequently affected by typhoons and experienced 132 hazardous typhoons during 1951-2013 with an average of 2.13 times per year. The most intense landing typhoon recorded since 1950 that affected Pingyang County is Saomai (no. 0608), and the central pressure at the time of landing reached $920 \mathrm{hPa}$ with a wind speed of $60 \mathrm{~m} \mathrm{~s}^{-1}$. About $40 \%$ of the typhoons at the time of landing had a central air pressure lower than $965 \mathrm{hPa}$. The county has been affected by 20 typhoons with central air pressure in the range of 920 to $985 \mathrm{hPa}$ (average $-965 \mathrm{hPa}$ ) since 1990. Based on the actual need for responses to coastal storm surges, this study considered typhoons with five different levels of intensity (Table 4), which were based on the central air pressure during landfall with reference to the Technical Guidelines 

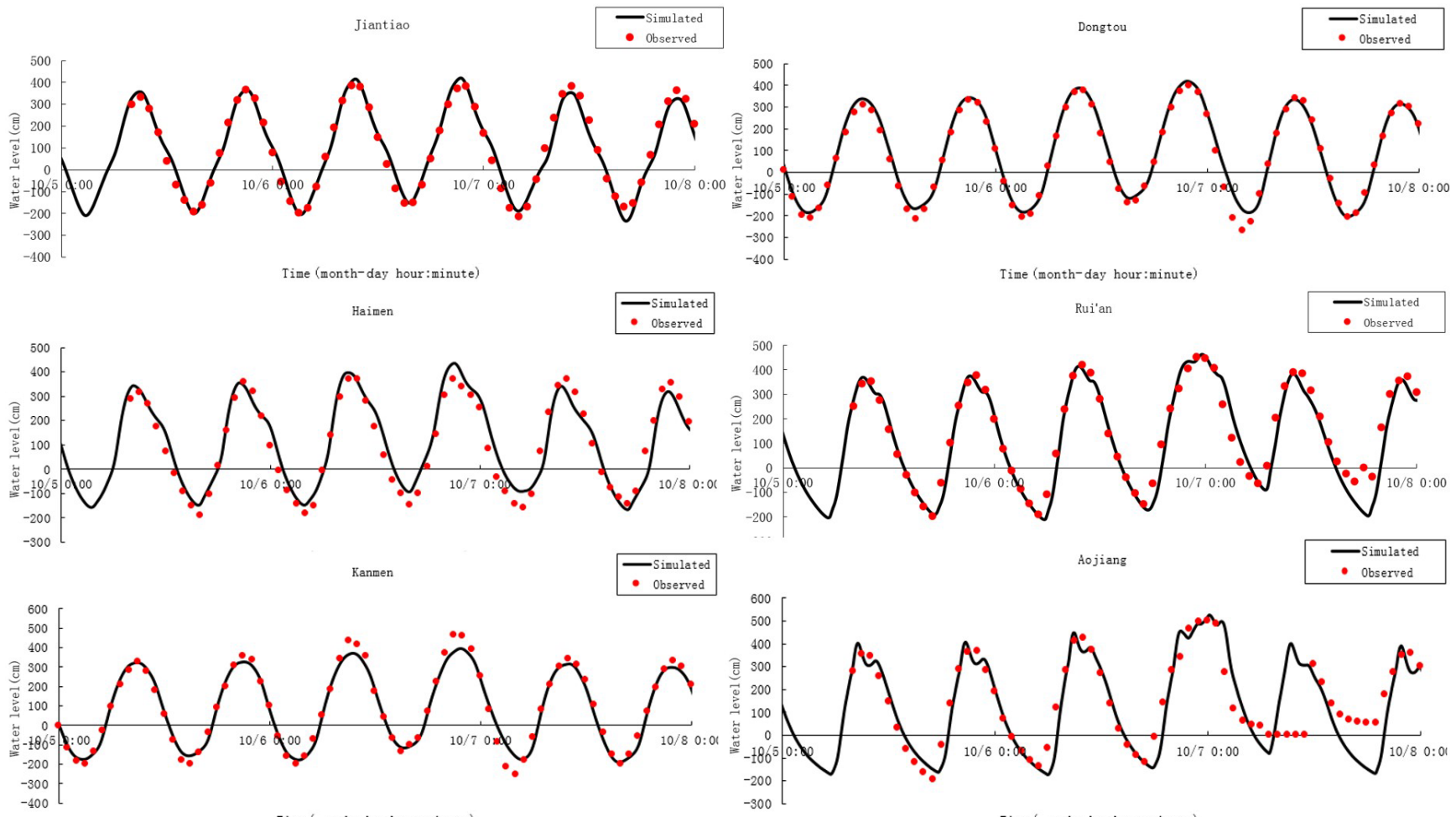

Figure 5. Verification of the high tide level for tidal stations affected by the storm surge caused by Typhoon Fitow (no. 1323).
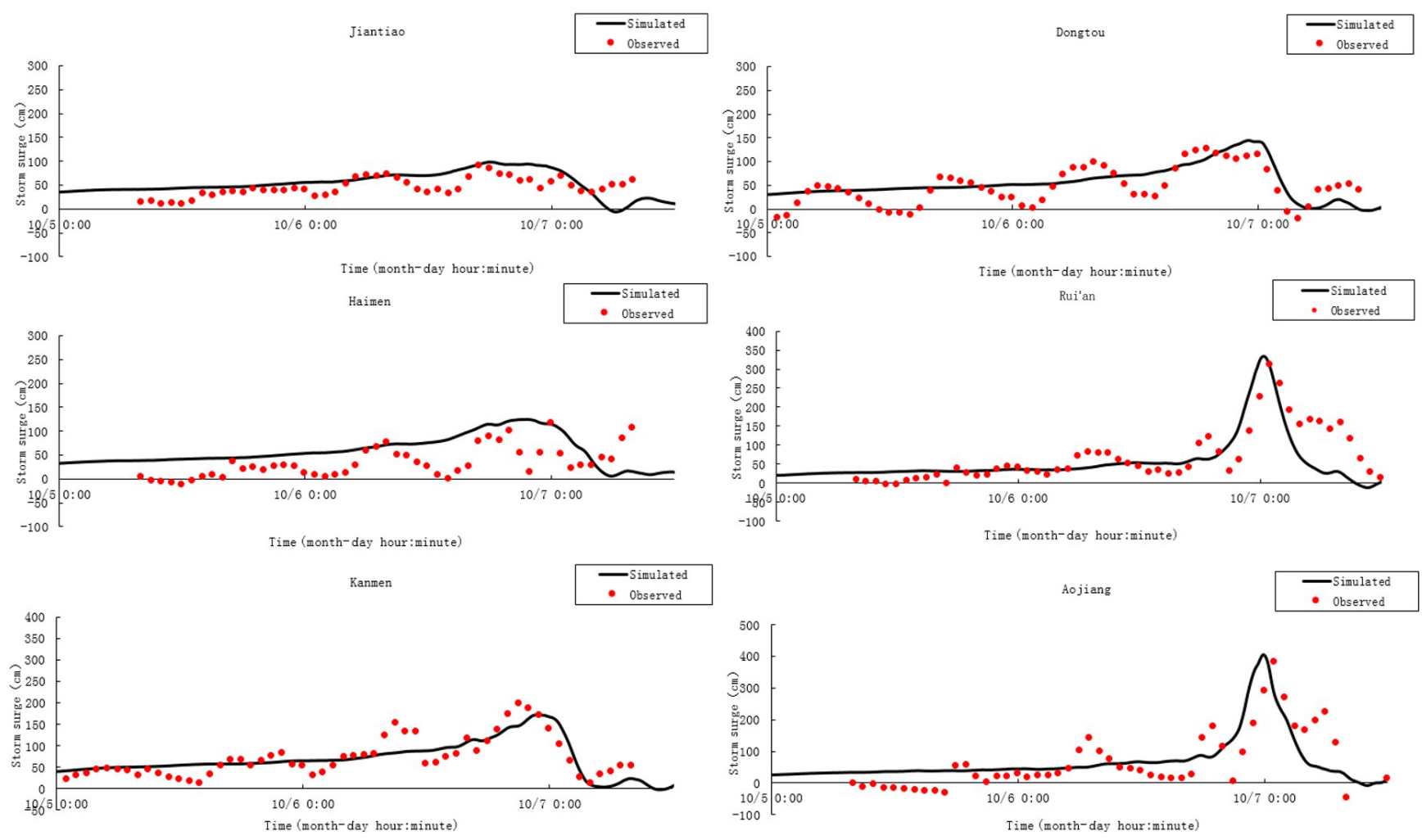

Figure 6. Verification of the storm surge for tidal stations affected by the storm surge caused by Typhoon Fitow (no. 1323). 

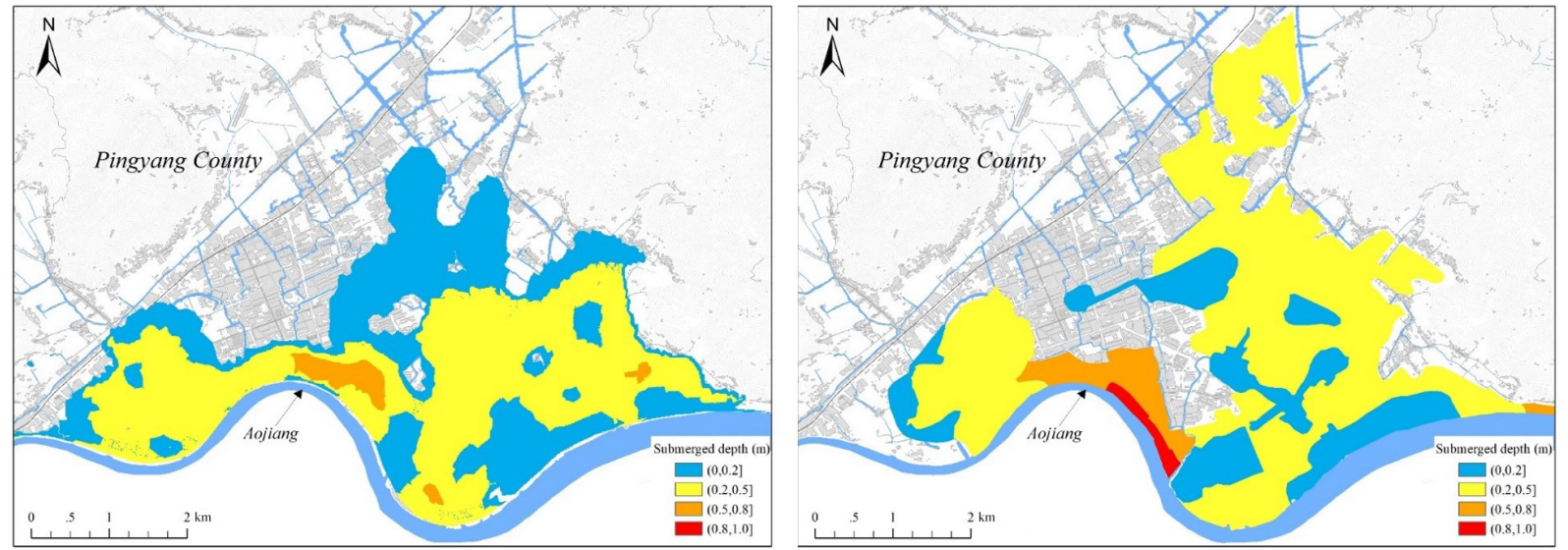

Figure 7. (a) Simulated inundated area and (b) surveyed inundated area during Typhoon Fitow.

Table 2. Error statistics in terms of maximum water level during landfall of 20 typical typhoons (unit $-\mathrm{cm}$ ).

\begin{tabular}{lrrrrrrr}
\hline & Jiantiao & Haimen & Kanmen & Dongtou & Rui'an & Ao Jiang & Average \\
\hline 9015 & - & - & 3 & 2 & -23 & - & 9 \\
9216 & -6 & -24 & - & -15 & -1 & 4 & 10 \\
9219 & 20 & 23 & -1 & 18 & -7 & -3 & 12 \\
9417 & 14 & 4 & - & 31 & 11 & -3 & 11 \\
9608 & -19 & -20 & - & -30 & -25 & 2 & 19 \\
9711 & -17 & 11 & -24 & - & -24 & -31 & 22 \\
0004 & 16 & 25 & -20 & 1 & 14 & 15 & 15 \\
0008 & 12 & -1 & -26 & 12 & 7 & 13 & 12 \\
0108 & 18 & 14 & 16 & 17 & 24 & 22 & 19 \\
0216 & 5 & -16 & -11 & 17 & 21 & 17 & 15 \\
0505 & 31 & -5 & -31 & -33 & -15 & 31 & 24 \\
0509 & -17 & -17 & -14 & -14 & 2 & 7 & 12 \\
0515 & 0 & 28 & -17 & -4 & 1 & 6 & 9 \\
0604 & -2 & -14 & -24 & -9 & -17 & -1 & 11 \\
0608 & 1 & -13 & -2 & 3 & 15 & 23 & 10 \\
0713 & 16 & 4 & 10 & -1 & 25 & 26 & 14 \\
0716 & 19 & 8 & 14 & 13 & 21 & 15 & 15 \\
0908 & 20 & 22 & - & - & 10 & 2 & 14 \\
1209 & 6 & -10 & -21 & -10 & 16 & 15 & 13 \\
1323 & 26 & 31 & -55 & 19 & -8 & -17 & 26 \\
\hline Average & 14 & 15 & 18 & 14 & 14 & 13 & 15 \\
\hline
\end{tabular}

Note: “-” means no observational value.

for Risk Assessment and Zoning of Marine Disaster Part 1: Storm Surge (Liu et al., 2018).

\subsubsection{Typhoon track}

This study selected the two typhoons that had the most severe impact on Pingyang County and that generated the most significant storm surge in history, i.e., Typhoon Fred (no. 9417) and Typhoon Saomai (no. 0608) as shown in Fig. 8. Typhoon Fred caused the most severe storm surge in central and southern parts of Zhejiang Province (including Pingyang County) since 1949. The minimum central air pressure of this typhoon was $935 \mathrm{hPa}$; however, when making landfall near Rui'an, the central air pressure was $960 \mathrm{hPa}$ and the radius of maximum wind speed was approximately $50 \mathrm{~km}$. This typhoon landed at the time of the highest astronomical tide, and it generated the highest water level ever recorded in the coastal area, causing the water level at Aojiang Station to increase to up to $6.56 \mathrm{~m}$. Typhoon Saomai had the lowest central air pressure and the fastest wind speed of any typhoon since 1949 . The minimum central air pressure reached $915 \mathrm{hPa}$; however, when making landfall near the Cangnan tidal station, the central air pressure was $920 \mathrm{hPa}$ and the radius of maxi- 
2784 X. Shi et al.: Simulation of storm surge inundation under different typhoon intensity scenarios: Pingyang County

Table 3. Error statistics in terms of the maximum storm surge during landfall of 20 typical typhoons (unit $-\mathrm{cm}$ ).

\begin{tabular}{lrrrrrrr}
\hline & Jiantiao & Haimen & Kanmen & Dongtou & Rui'an & Ao Jiang & Average \\
\hline 9015 & - & - & -11 & -17 & -9 & - & 12 \\
9216 & -8 & -6 & -34 & -6 & -2 & -12 & 11 \\
9219 & 6 & 15 & -11 & 14 & 13 & 20 & 13 \\
9417 & -21 & -17 & -2 & - & -20 & -8 & 14 \\
9608 & -10 & -21 & -35 & -10 & -16 & -10 & 17 \\
9711 & 23 & 21 & -15 & -20 & -1 & -7 & 15 \\
0004 & 10 & 12 & -14 & 7 & 10 & -4 & 10 \\
0008 & 3 & -2 & -2 & 16 & -2 & 10 & 6 \\
0108 & 10 & 10 & 1 & 27 & 5 & 3 & 9 \\
0216 & 11 & 2 & 2 & 2 & 26 & 19 & 10 \\
0505 & -15 & -5 & -26 & -10 & -26 & -38 & 20 \\
0509 & -8 & 17 & -14 & 8 & -15 & -10 & 12 \\
0515 & 9 & 12 & -20 & -12 & -23 & -10 & 14 \\
0604 & -10 & -21 & -35 & 10 & 15 & 9 & 17 \\
0608 & -1 & 5 & 10 & -13 & 13 & -3 & 8 \\
0713 & 21 & -2 & -8 & 28 & 17 & 18 & 16 \\
0716 & 9 & 15 & 20 & 2 & 17 & 21 & 14 \\
0908 & -42 & -3 & - & - & -6 & -5 & 14 \\
1209 & - & - & -6 & - & 10 & 13 & 10 \\
1323 & 5 & 7 & -27 & 12 & 21 & 19 & 15 \\
\hline Average & 12 & 11 & 15 & 13 & 13 & 13 & 13 \\
\hline
\end{tabular}

Note: “-” means no observational value.

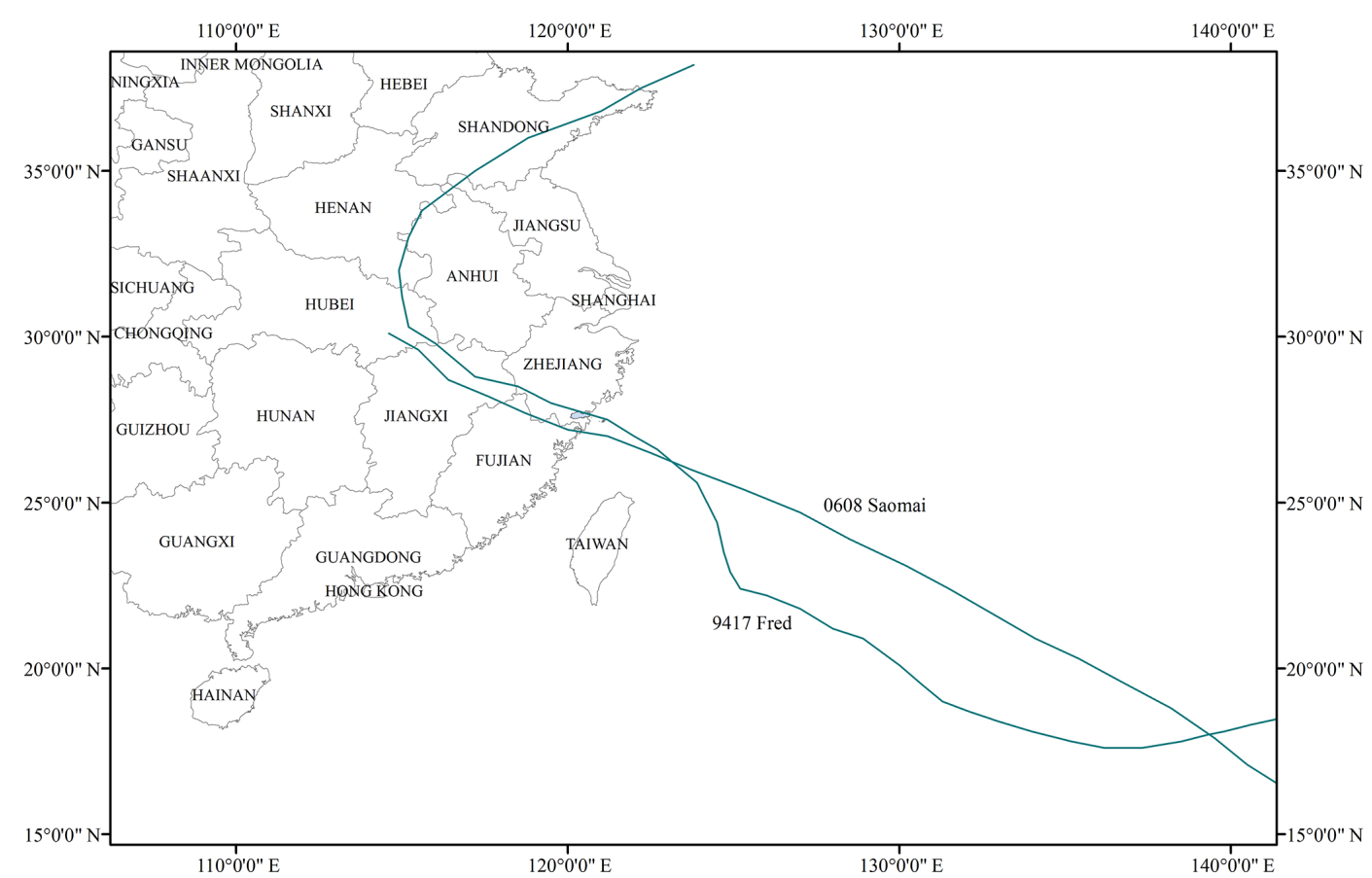

Figure 8. Typhoon tracks of 9417 Fred and 0608 Saomai. 


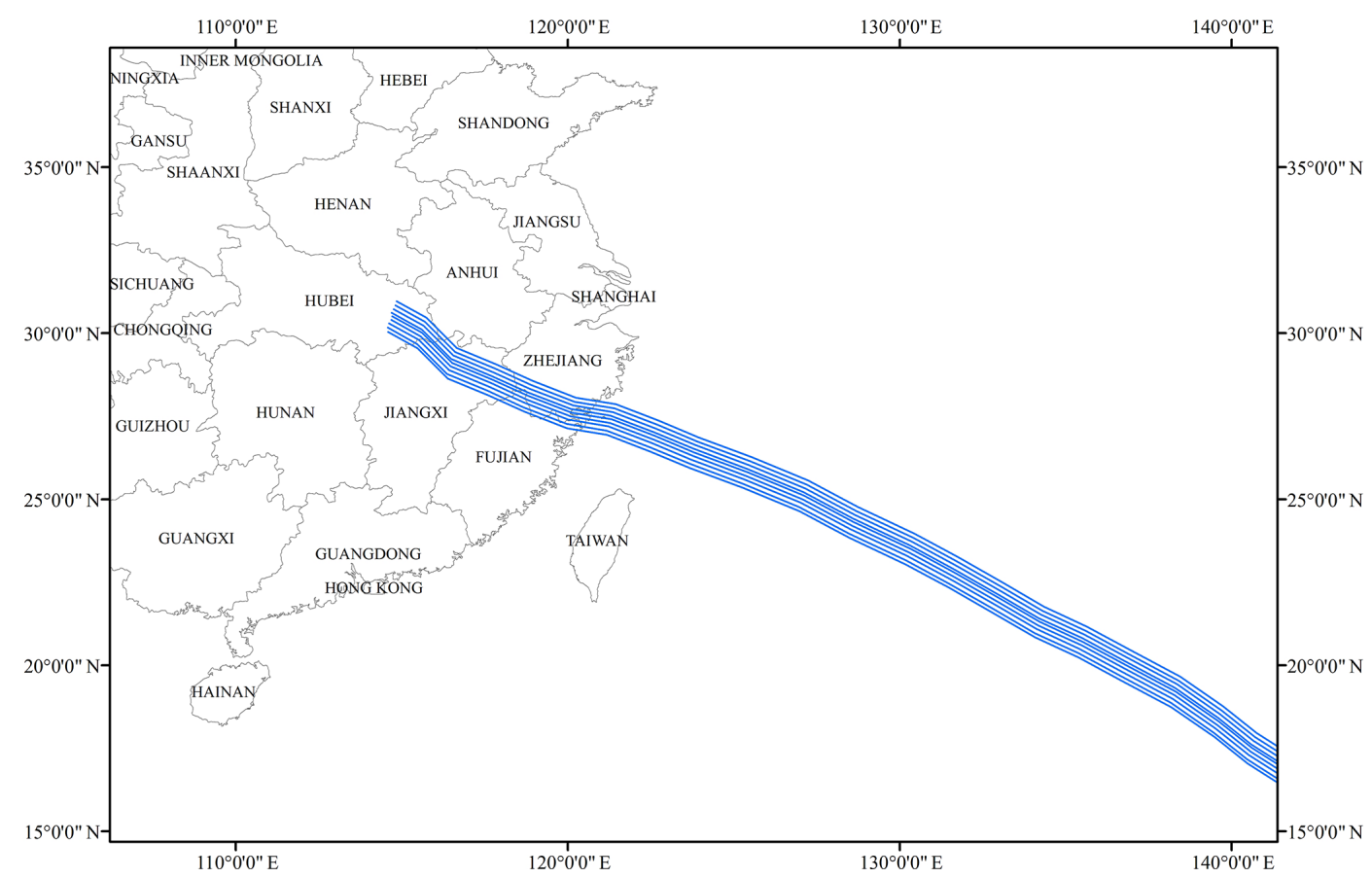

Figure 9. Designed-typhoon track set over Pingyang County.

Table 4. Typhoon intensity scenarios.

\begin{tabular}{llllll}
\hline Typhoon intensity & I & II & III & IV & V \\
\hline Maximum wind force & Level 12-13 & Level 14-15 & Level 16 & Level 17 & $\begin{array}{l}\text { Above 17 } \\
\text { Minimum air central pressure (hPa) }\end{array}$ \\
965 & 945 & 935 & 925 & 915 \\
\hline
\end{tabular}

mum wind speed was approximately $15 \mathrm{~km}$. Before making landfall, both typhoons traveled in a direction perpendicular to the shoreline, conducive to generating the greatest storm surge.

To determine which of these two typhoons had the track that caused the larger storm surge in Pingyang County under the same conditions, both were assumed to have a central air pressure of $915 \mathrm{hPa}$, radius of maximum wind speed of $36 \mathrm{~km}$, and constant direction of movement. The track of Typhoon Fred was translated to the landing site of Typhoon Saomai. The results showed that the maximum storm surge of Typhoon Fred and Typhoon Saomai was 7.22 and 7.47 m, respectively, at Aojiang and 7.00 and $7.03 \mathrm{~m}$, respectively, at Rui'an. As the storm surge associated with Typhoon Saomai was slightly larger, the track of this typhoon was selected as the designed-typhoon track. The designed-typhoon track was translated to a position in the middle of Pingyang County and then translated to the sides by a distance of 0.25 times the radius of maximum wind speed, until the track combination that maximized the storm surge in each coastal area of Pingyang County was determined (Fig. 9). This track was then used for the inundation superposition calculation.

\subsubsection{Radius of maximum wind speed}

The radius of maximum wind speed which is the radius from the typhoon's center to the position where the maximum wind speed occurs was used to indicate the "size" of the typhoon. The radius of maximum wind speed of a typhoon is an important factor for the simulating of storm surge height and coastal inundation extent. Collecting the historical radius of maximum wind speed data measured in the northwest Pacific hurricane records (2001-2018) from the Joint Typhoon Warning Center (Joint Typhoon Warning Center, 2018), it can be seen that the radius of maximum wind speed is inversely proportional to the central pressure difference (Fig. 10). The radius of maximum wind speed has a strong relationship with the typhoon intensity, and an empirical formula was used to calculate the radius of maximum wind speed as below:

$R=R_{0}-0.4\left(P_{0}-900\right)+0.01\left(P_{0}-900\right)^{2}$,

where $P_{0}$ is the central air pressure (hPa), $R$ is the radius of maximum wind speed, and $R_{0}$ is an empirical constant. The recommended value is 40 , although this can also be adjusted by the fitting accuracy of the air pressure or the wind speed. 


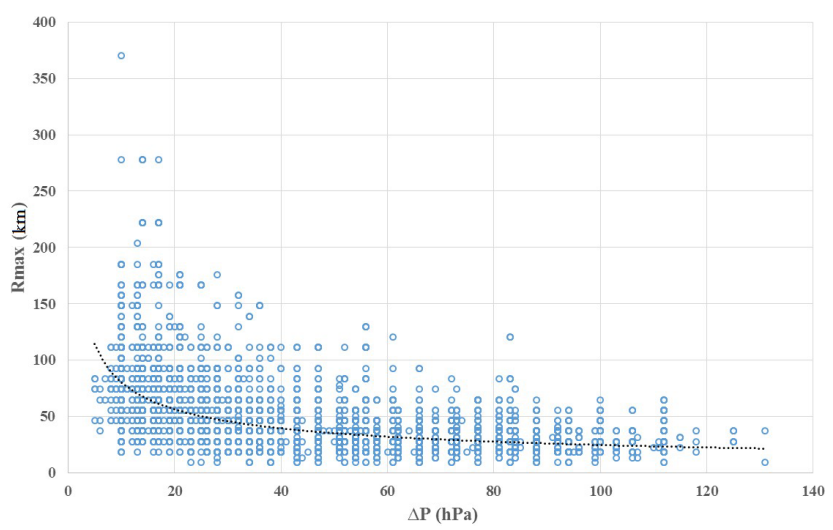

Figure 10. The relation between the central pressure difference $(\Delta P)$ and the radius of maximum wind $\left(R_{\max }\right)$.

Thus, the radius of maximum wind speed can be calculated from the central air pressure of the typhoons with five different intensities at the time of landfall, i.e., $56,42,38,36$, and $36 \mathrm{~km}$.

\subsubsection{Astronomical tide}

The coupling of the astronomical tide and the storm surge was performed for simulation of the total elevation and range of inundation. The monthly averaged high tide levels of the previous 19 years during June-October at the representative tidal stations in the study area were selected as the astronomical tide levels that were coupled with the storm surge at peak surge times in the local coastal area. The astronomical tide levels at Dongtou Station on the northern side of Pingyang County and at Pipamen Station on the southern side were 2.46 and $2.33 \mathrm{~m}$, respectively. The larger value of $2.46 \mathrm{~m}$ was taken as the astronomical tidal level of the storm surge in the storm surge numerical model for the inundation simulation.

\subsubsection{Upstream flood runoff}

The upstream flood is a factor required for numerical simulation of storm surges in estuary areas. Analysis of measured data and model studies indicate that the high-water level in an estuary area is controlled mainly by the astronomical tide and the typhoon-induced storm surge. The peak flow in an estuary has obvious influence on the high-water level during the passage of a typhoon (Sun et al., 2017). The storm surgerunoff interaction in an estuary area increases the tidal level of a typhoon-induced storm surge, resulting in a larger hazard (Zheng et al., 2013). The larger the volume of runoff is, the greater the tidal level in the estuary area will be (Hao et al., 2018). The Feiyun Jiang and Ao Jiang, located on the northern and southern sides of Pingyang County, respectively, are the main rivers that affect the level of flooding in Pingyang County. In this study, the superimposed upstream flood in the numerical simulation of storm surges was the average peak flows in the estuary areas of these rivers in the period of the selected historical typhoons during April-October, i.e., 1717 and $2348 \mathrm{~m}^{3} \mathrm{~s}^{-1}$ for the Ao Jiang and Feiyun Jiang, respectively.

\subsubsection{Seawall collapse scenario}

The seawall is an important barrier against storm surges, and excessive overtopping of waves is the main cause of seawall collapse. Overtopping waves flush the seawall or the landward slope, forming a scour pit. As the scour pit grows, the upper structure of the seawall loses support and becomes unstable (Sun et al., 2015; Zhang et al., 2017). In the design of the majority of seawalls in China's coastal areas, the wave overtopping rate, which is determined based on tide level, wave height, and seawall structure, is used as a controlling indicator and as a parameter to judge whether a seawall will collapse. According to the results of physical model tests, seawall collapse will occur when the wave overtopping rate of the coastal seawall in Pingyang County exceeds $0.05 \mathrm{~m}^{3} \mathrm{~s}^{-1}$ (Zhejiang Institute of Hydraulics and Estuary, 2018). Once seawall collapse is determined in the numerical simulation, it will occur instantaneously without consideration of its process. After seawall collapse occurs in the numerical simulation, the ground elevation within the seawall is taken as the shoreline elevation, and the width of seawall collapse is determined by the wave overtopping rate at the representative point on the seawall. Each representative point represents a section of seawall.

\section{Calculation results}

To further analyze the accuracy of the calculation results derived from the simulations, 22 representative reference points were set along the Pingyang County coast to obtain the desired data (Fig. 11). The calculated maximum water level at each reference point for typhoons of different intensity is shown in Table 5. It can be seen that for the eastern coastal area of Pingyang County, the maximum water level of the representative points appeared near the radius of maximum wind speed on the southern side of the point of landfall of the typhoon. For the 915 and $925 \mathrm{hPa}$ super typhoons, the typhoon track was moved southward from the reference position of Pingyang, reaching the Feiyun Jiang estuary by $25 \mathrm{~km}$, where the maximum water level of $7.78 \mathrm{~m}$ appeared; reaching the Feiyun Jiang estuary and the eastern coast of Pingyang by $30 \mathrm{~km}$, where the maximum water level of $7.88 \mathrm{~m}$ appeared; and reaching the Ao Jiang estuary by $40 \mathrm{~km}$, where the maximum water level of $7.90 \mathrm{~m}$ appeared. For the 935, 945, and $965 \mathrm{hPa}$ typhoons, the typhoon tracks' corresponding maximum water level moved further southward as the radius of maximum wind speed increased. For example, the $965 \mathrm{hPa}$ typhoon should move southward by $89 \mathrm{~km}$ from the reference position to reach the eastern coast 


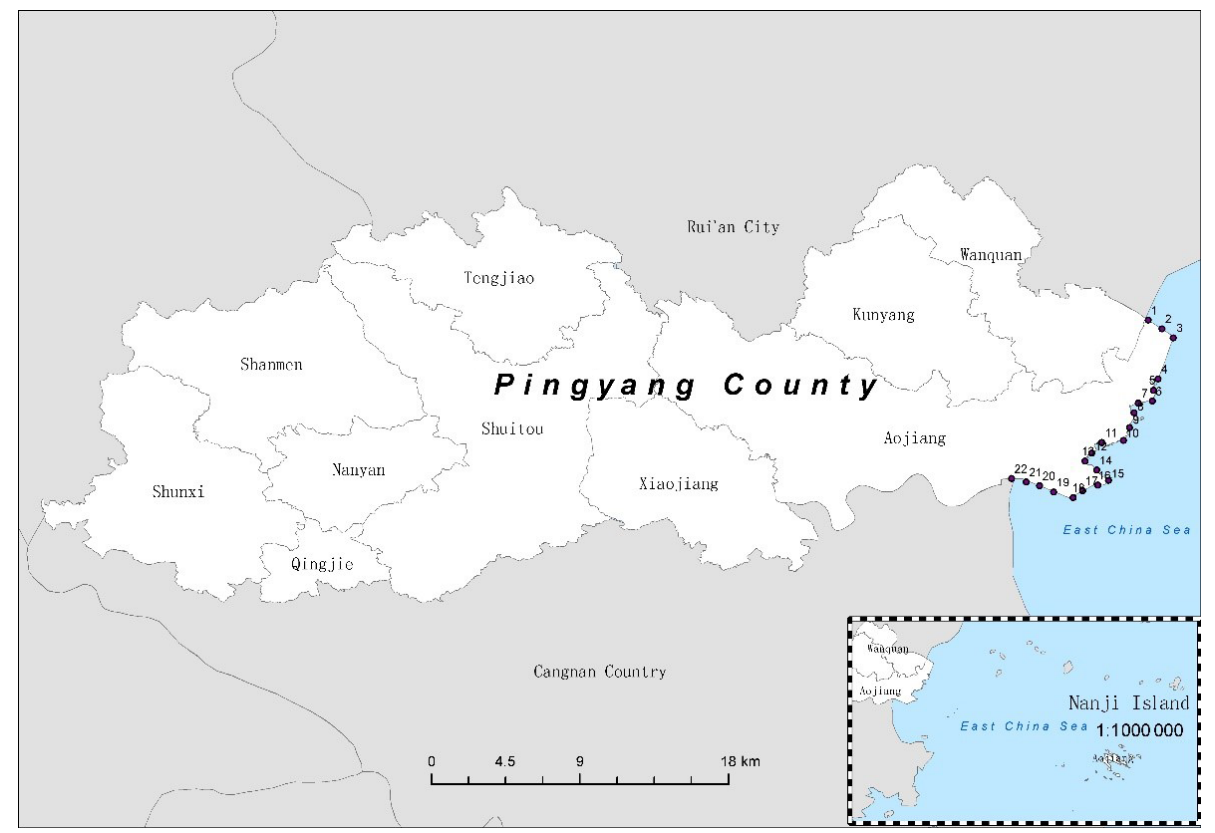

Figure 11. The reference points along Pingyang coast.

of Pingyang, where the maximum water level would appear. Overall, the calculated maximum water level for the $925 \mathrm{hPa}$ typhoon was approximately 0.17 to $0.53 \mathrm{~m}$ lower than that of the $915 \mathrm{hPa}$ typhoon but approximately 0.29 to $0.51 \mathrm{~m}$ higher than that of the $935 \mathrm{hPa}$ typhoon. The calculated maximum water level for the $945 \mathrm{hPa}$ typhoon was approximately 0.28 to $0.5 \mathrm{~m}$ lower than that of the $935 \mathrm{hPa}$ typhoon but approximately 0.71 to $1.09 \mathrm{~m}$ higher than that of the $965 \mathrm{hPa}$ typhoon.

Storm surge inundation was calculated for the unfavorable tracks corresponding to the five typhoon intensity scenarios. The storm tide levels caused by each unfavorable track were all the maximum storm surges of the 22 representative points around Pingyang. Therefore, it can be considered that the inundation superposition of these unfavorable tracks represented the maximum storm surge inundation range and the water depth distribution in Pingyang County associated with the typhoons of different intensity. The range of inundation in Pingyang County by the storm surges associated with the five typhoons of different intensity is shown in Fig. 12. It can be seen that the inundation range increased with the increase in typhoon intensity. Based on Fig. 12, Table 6 shows the statistical results of the maximum inundated area corresponding to the five typhoon scenarios. It can be seen that the area of Pingyang County inundated by the storm surge associated with the $915 \mathrm{hPa}$ typhoon and the most unfavorable track reached $233 \mathrm{~km}^{2}$. The inundated areas included most parts of the town of Aojiang town, eastern areas of Wanquan, and northern areas of Songbu, as well as parts of Kunyang and Shuitou, including administrative villages such as Qianjie and Jinmei.
Table 5. Statistical results of maximum water level associated with unfavorable tracks of typhoons under different intensity scenarios.

\begin{tabular}{lccccc}
\hline $\begin{array}{l}\text { Reference } \\
\text { point no. }\end{array}$ & $915 \mathrm{hPa}$ & $925 \mathrm{hPa}$ & $935 \mathrm{hPa}$ & $945 \mathrm{hPa}$ & $965 \mathrm{hPa}$ \\
\hline 1 & & & & & \\
2 & 7.61 & 7.28 & 6.90 & 6.48 & 5.53 \\
3 & 7.59 & 7.26 & 6.87 & 6.46 & 5.51 \\
4 & 7.60 & 7.24 & 6.85 & 6.43 & 5.48 \\
5 & 7.62 & 7.24 & 6.83 & 6.42 & 5.46 \\
6 & 7.65 & 7.25 & 6.82 & 6.40 & 5.44 \\
7 & 7.70 & 7.27 & 6.82 & 6.39 & 5.42 \\
8 & 7.79 & 7.32 & 6.86 & 6.41 & 5.42 \\
9 & 7.85 & 7.37 & 6.89 & 6.44 & 5.44 \\
10 & 7.87 & 7.38 & 6.90 & 6.45 & 5.44 \\
11 & 7.88 & 7.38 & 6.90 & 6.45 & 5.44 \\
12 & 7.88 & 7.38 & 6.91 & 6.45 & 5.45 \\
13 & 7.87 & 7.36 & 6.90 & 6.44 & 5.44 \\
14 & 7.91 & 7.39 & 6.94 & 6.47 & 5.46 \\
15 & 7.58 & 7.17 & 6.72 & 6.27 & 5.37 \\
16 & 7.66 & 7.30 & 6.84 & 6.38 & 5.40 \\
17 & 7.66 & 7.43 & 6.95 & 6.48 & 5.45 \\
18 & 7.79 & 7.56 & 7.06 & 6.58 & 5.52 \\
19 & 7.90 & 7.69 & 7.18 & 6.69 & 5.60 \\
20 & 7.81 & 7.62 & 7.15 & 6.68 & 5.68 \\
21 & 7.64 & 7.47 & 7.05 & 6.64 & 5.72 \\
22 & 7.44 & 7.27 & 6.91 & 6.57 & 5.75 \\
& 7.36 & 7.05 & 6.76 & 6.49 & 5.77 \\
\hline
\end{tabular}




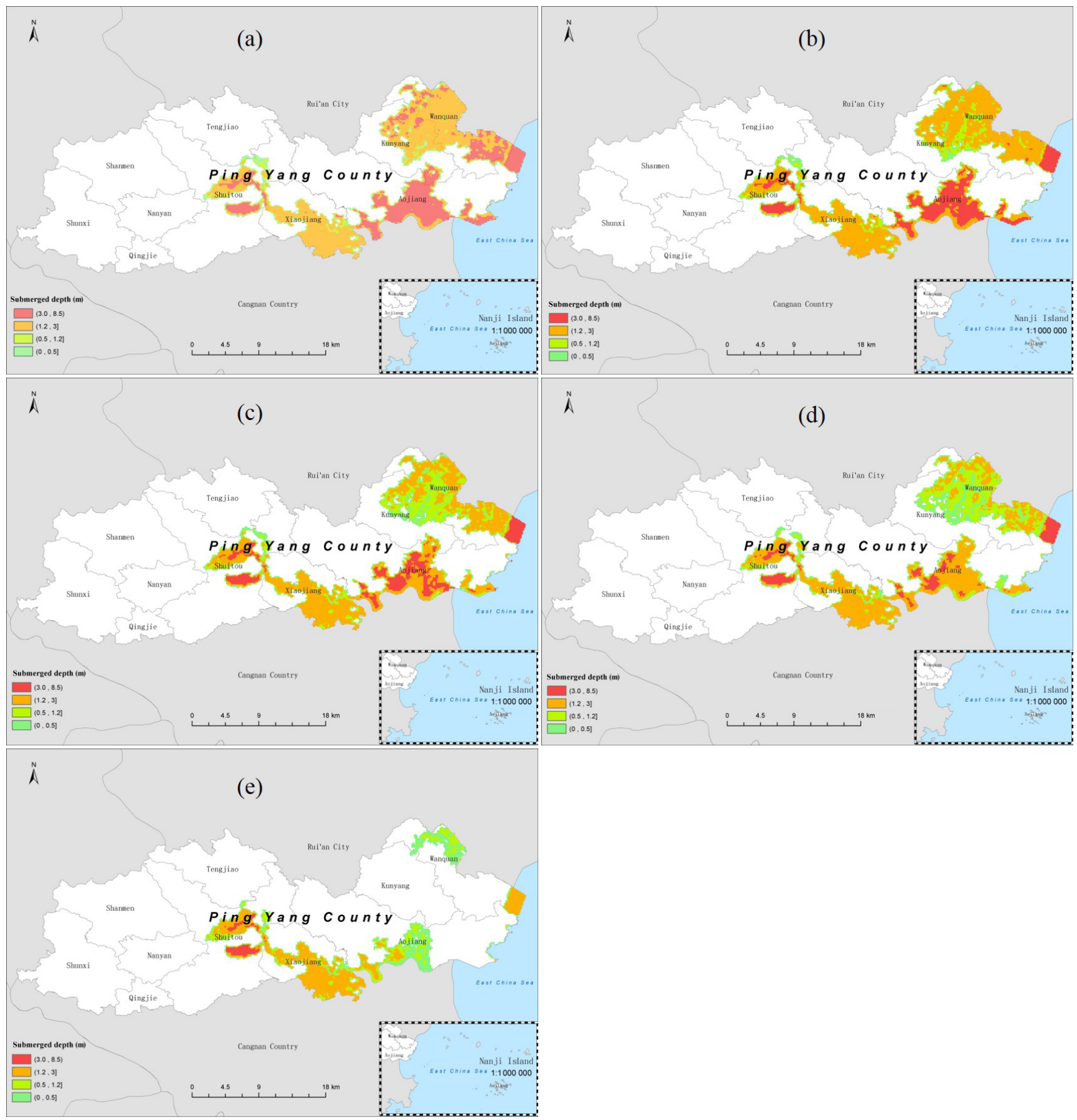

Figure 12. Inundation range and water depth distribution of storm surges associated with typhoons of different intensity: (a) $915 \mathrm{hPa}$, (b) $925 \mathrm{hPa}$, (c) $935 \mathrm{hPa}$, (d) $945 \mathrm{hPa}$, and (e) $965 \mathrm{hPa}$.

\section{Conclusion and discussion}

This study contributed to the methodology of storm surge inundation simulation caused by different intensities of typhoons. A high-precision numerical model for simulating storm surges was established and validated by observational data and by field surveying inundated areas afterward. Us- ing these key parameters including typhoon tracks, radius of maximum wind speed, astronomical tide, and upstream flood runoff as driving factors, the inundation extents and depths in Pingyang County corresponding to the storm surges under different typhoon intensity scenarios were simulated in combination with the storm surge numerical model. The seawall collapse was considered and determined by wave overtop- 
Table 6. Extension of inundated areas associated with different typhoon intensity scenarios for different water level thresholds (unit $-\mathrm{km}^{2}$ ).

\begin{tabular}{lrrrrc}
\hline $\begin{array}{l}\text { Typhoon } \\
\text { force }\end{array}$ & $>3.0 \mathrm{~m}$ & $1.2-3.0 \mathrm{~m}$ & $0.5-1.2 \mathrm{~m}$ & $\begin{array}{r}\text { Below } \\
0.5 \mathrm{~m}\end{array}$ & $\begin{array}{c}\text { Total } \\
\text { area }\end{array}$ \\
\hline $915 \mathrm{hPa}$ & 69.28 & 144.27 & 11.75 & 7.86 & 233.16 \\
$925 \mathrm{hPa}$ & 44.93 & 121.10 & 22.74 & 10.97 & 199.74 \\
$935 \mathrm{hPa}$ & 31.68 & 104.63 & 40.24 & 17.03 & 193.58 \\
$945 \mathrm{hPa}$ & 19.68 & 97.55 & 48.33 & 22.98 & 188.54 \\
$965 \mathrm{hPa}$ & 5.25 & 52.54 & 22.58 & 23.14 & 103.51 \\
\hline
\end{tabular}

ping. Once the wave overtopping rate exceeds $0.05 \mathrm{~m}^{3} \mathrm{~s}^{-1}$, the seawall fails to prevent inundation caused by storm surges. The obtained results could serve as a basis for developing a methodology for storm surge disaster risk assessment in coastal areas. The study provides an insight into the spatial distribution of the areas potentially endangered by the typhoon-related flooding. It can be helpful for further hazard and risk assessments for urban planning, emergency procedures, and insurance.

The inundation extent of a storm surge is related to many factors (Petroliagkis, 2018). In this study, the process of inundation is independent of the duration of the storm surge event, and a simplified sudden collapse of the seawall is assumed, which could increase the inundation range of the simulated result. The water level in the towns of Shuitou and Xiaojiang in Pingyang County is mainly caused by the upstream flood of the Ao Jiang. Consequently, the inundation in these two areas is directly related to upstream flood runoff. The impact of the upstream flood was only considered as the average of the flood peak flow during the storm surge in this study. The water level and inundation areas caused by the large astronomical tide due to the superposition of the extreme flood scenarios might be more unfavorable than the simulated storm surge with the superimposed average of the flood peak runoff, which might result in uncertainty in the calculation results. We will analyze the quantitative response relationship between typhoon intensity at landfall and upstream flood runoff and propose a quantitative method for setting flood runoff upstream of the estuary area in further research.

This paper presents a deterministic method for setting key parameters under typhoon intensity scenarios assuming that these factors (e.g., typhoon track, radius of maximum wind speed, astronomical tide, and upstream flood runoff) are independent. However, any correlation between these parameters is ignored. The occurrence probability of parameter combinations is difficult to evaluate. The joint probability method is an efficient way to determine the base flood elevation due to storm surges (Yang et al., 2019), and the joint probability among these factors could be established (e.g., using the copula method) to calculate the occurrence of extreme storm surge events.
Data availability. All data used during the study are available from the corresponding author on request.

Author contributions. XS prepared the manuscript with contributions from all co-authors and set the key parameters. PY, FC, XW, and $\mathrm{WC}$ performed the numerical simulation. $\mathrm{ZG}$ provided the inundated results. ZS provided the tidal observational data. JZ conducted this research and designed the experiments.

Competing interests. The authors declare that they have no conflict of interest.

Acknowledgements. This work was funded by the National Natural Science Foundation of China (41701596) and the Open-end Fund of the Key Laboratory of Coastal Disaster and Protection (Hohai University) of the Ministry of Education (201909).

Financial support. This research has been supported by the National Natural Science Foundation of China (grant no. 41701596) and the Open-end Fund of the Key Laboratory of Coastal Disaster and Protection (Hohai University) of the Ministry of Education (grant no. 201909).

Review statement. This paper was edited by Piero Lionello and reviewed by Wei-Bo Chen and one anonymous referee.

\section{References}

Booij, N., Ris R. C., and Holthuijsen, L. H.: A third-generation wave model for coastal regions: 1 . Model description and validation, J. Geophys. Res.-Oceans, 104, 7649-7666, 1999.

Chen, F. Y., Yu, P. B., Wu, X. G., and Zhu, Y. Z.: Refined risk assessment of storm surge disaster in coastal plain: a case study of Pingyang County, J. Trop. Meteorol., 25, 304-311, https://doi.org/10.16555/j.1006-8775.2019.03.002, 2019.

Fang, J., Sun, S., Shi, P., and Wang, J. A.: Assessment and Mapping of Potential Storm Surge Impacts on Global Population and Economy, Int. J. Disast. Risk Sci., 5, 323-331, https://doi.org/10.1007/s13753-014-0035-0, 2014.

Gao, Y., Wang, H., Liu, G. M., Sun, X. Y., Fei, X. Y., and Wang, P. T.: Risk assessment of tropical storm surges for coastal regions of China, J. Geophys. Res.-Atmos., 119, 5364-5374, https://doi.org/10.1002/2013JD021268, 2014.

Hao, Z., Hao, F., Singh, V. P., Xia, Y., Shi, C., and Zhang, X.: A multivariate approach for statistical assessments of compound extremes, J. Hydrol., 565, 87-94, https://doi.org/10.1016/j.jhydrol.2018.08.025, 2018.

Jelesnianski, C. P.: A numerical calculation of storm tides induced by a tropical storm impinging on a continental shelf, Mon. Weather Rev., 93, 343-358, https://doi.org/10.1175/15200493(1993)0932.3.CO;2, 1965. 
Joint Typhoon Warning Center: Western North Pacific Ocean Best Track Data, Naval Oceanography Portal, available at: https: //www.metoc.navy.mil/jtwc/jtwc.html last access: 5 September 2018.

Lin, N., Emanuel, K. A., Smith, J. A., and Vanmarcke, E.: Risk assessment of hurricane storm surge for New York City, J. Geophys. Res.-Atmos., 115, D18121, https://doi.org/10.1029/2009JD013630, 2010.

Liu, Q. Z., Shi, X. W., and Guo, Z. X.: Technical guidelines for risk assessment and zoning of marine disaster Part 1: Storm surge, Standards Press of China, Beijing, 2018.

Ministry of Natural Resources of China: Chinese marine disaster bulletin of 2018, Beijing, 2019.

Petroliagkis, T. I.: Estimations of statistical dependence as joint return period modulator of compound events - Part 1: Storm surge and wave height, Nat. Hazards Earth Syst. Sci., 18, 1937-1955, https://doi.org/10.5194/nhess-18-1937-2018, 2018.

Powell, M., Soukup, G., Cocke, S., Gulati, S., Morisseau-Leroy, N., and Hamid, S.: State of florida hurricane loss projection model: atmospheric science component, J. Wind Eng. Indust. Aerodynam., 93, 651-674, https://doi.org/10.1016/j.jweia.2005.05.008, 2005.

Shi, X. W., Tan, J., Guo, Z. X., and Liu, Q. Z.: A Review of Risk Assessment of Storm Surge Disaster, Adv. Earth Sci., 28, 806-874, https://doi.org/10.11867/j.issn.1001-8166.2013.08.0866, 2013.

Shi, X. W., Liu, S., Yang, S. N., Liu, Q. Z., Tan, J., and Guo, Z. X.: Spatial-temporal distribution of storm surge damage in the coastal area of China, Nat. Hazards, 79, 237-247, https://doi.org/10.1007/s11069-015-1838-z, 2015.

Shi, X. W., Han, Z. Q., Fang, J. Y., Tan, J., Guo, Z. X., and Sun, Z. L.: Assessment and zonation of storm surge hazards in the coastal areas of China, Nat. Hazards, 100, 39-48, https://doi.org/10.1007/s11069-019-03793-z, 2020a.

Shi, X. W., Qiu, J. F., Chen, B. R., Zhang, X. J., Guo, H. S., Wang, J., and Bei, Z. Y.: Storm surge risk assessment method for a coastal county in China: A case study in Jinshan District, Shanghai, Stoch. Environ. Res. Risk A., 34, 627-640, 2020 b.

Sun, Z., Huang, S., Nie, H., Jiao, J., Huang, S., Zhu, L., and $\mathrm{Xu}, \mathrm{D}$.: Risk analysis of seawall overflowed by storm surge during super typhoon, Ocean Eng., 107, 178-185, https://doi.org/10.1016/j.oceaneng.2015.07.041, 2015.
Sun, Z. L., Huang, S. J., Jiao, J. G., and Nie, H.: Effect of Runoff on Typhoon Storm Surge in Estuaries, J. Tianjin Univers. (Sci. Technol.), 50, 519-526, https://doi.org/10.11784/tdxbz201604050, 2017.

Tomohiro, Y., Yuta, T., Nobuhito, M., and Hajime, M.: A Stochastic Typhoon Model Applicable to Storm Surge and Wave Simulations for Climate Change Projection, J. Jpn. Soc. Civ. Eng. Ser. B2, 66, 1241-1245, https://doi.org/10.2208/kaigan.66.1241, 2010.

Wahl, T., Mudersbach, C., and Jensen, J.: Statistical assessment of storm surge scenarios within integrated risk analyses, Coast. Eng. J., 57, 1540003, https://doi.org/10.1142/S0578563415400033, 2015.

Wang, Y. X., Duan, Y. H., Guo, Z. X., Chen, W. F., Zhang, X. H., and Han, Z. Y.: Deterministic-probabilistic approach for probable maximum typhoon-induced storm surge evaluation over wenchang in the south china sea, Estuar. Coast. Shelf Sci., 214, 161172, https://doi.org/10.1016/j.ecss.2018.09.025, 2018.

Wood, R. M., Drayton, M., Berger, A., Burgess, P., and Wright, T.: Catastrophe loss modelling of storm-surge flood risk in eastern england, Philos. T. Roy. Soc. A, 363, 1407-1422, https://doi.org/10.1098/rsta.2005.1575, 2005.

Yang, K., Paramygin, V., and Sheng, Y. P.: An objective and efficient method for estimating probabilistic coastal inundation hazards, Nat. Hazards, 99, 1105-1130, https://doi.org/10.1007/s11069019-03807-w, 2019.

Zhang, Y., Chen, G., Hu, J., Chen, X., Yang, W., Tao, A., and Zheng, J.: Experimental study on mechanism of sea-dike failure due to wave overtopping, Appl. Ocean Res., 68, 171-181, https://doi.org/10.1016/j.apor.2017.08.009, 2017.

Zhejiang Institute of Hydraulics and Estuary: Research Report on the Influenced Factors of Breakage Volume of Seawall Caused by Storm Surge Disasters, Hangzhou, 2018

Zheng, F. F., Westra, S., and Sisson, S. A.: Quantifying the dependence between extreme rainfall and storm surge in the coastal zone, J. Hydrol., 506, 172-187. https://doi.org/10.1016/j.jhydrol.2013.09.054, 2013. 